\title{
Two levels of personality: Temperament and values and their effects on hedonic and eudaimonic well-being
}

\author{
Agnieszka Bojanowska ${ }^{1} \cdot$ Konrad Piotrowski $^{1}$
}

Published online: 3 November 2018

(C) The Author(s) 2018

\begin{abstract}
According to McAdams and Pals, American Psychologist, 61(3), 204-217 (2006), personality is not only expressed through traits but also through characteristic adaptations, including values. In the present study we analyze how two aspects of personality temperament traits (Strelau 2008) and values (Schwartz 2007) - are related to hedonic and eudaimonic well-being. Earlier studies showed that temperament is linked to hedonic well-being, but the links between values and hedonic well-being are unclear. There is only little data on how traits and values are linked to eudaimonic well-being. We hypothesised that traits predict hedonic wellbeing, while values predict eudaimonic well-being because the roots of eudaimonia require the realization of one's potential that may be achieved through realization of value related goals, while hedonic well-being is more closely linked to stable differences in emotionality. 130 adults reported on their temperament, values, hedonic and eudaimonic well-being. We conducted hierarchical regressions for each well-being component. All components of hedonic well-being (positive affect, negative affect and satisfaction) were predicted by temperament only, while eudaimonic well-being was predicted by temperament and by value dimensions: positively by Openness to change, Self-transcendence, Conservation and negatively by Self-enhancement. This shows that mechanisms governing the experience of well-being are attached to at least two levels of personality - one stable and partly linked to human biology and the other to a culturally determined set of individual values. It also shows that the experience of eudaimonia relies on culturally acquired values, while hedonia may be determined more by temperamental dimensions.
\end{abstract}

Keywords Personality $\cdot$ Values $\cdot$ Hedonic well-being $\cdot$ Eudaimonic well-being

\section{Introduction}

For some time now studies have indicated, that people differ in their experience of well-being. These stable differences have been discussed in numerous conceptions, such as the 'baseline of well-being' concept (Brickman and Campbell 1971), the 'happy personality' (Costa and McCrae 1980) or the 'happy temperament' (Bojanowska and Zalewska 2016). All these theories indicate that stable personality traits are responsible for a significant variance of well-being experience, but more recent discussions have suggested that our understanding of the relationships between those two areas

Agnieszka Bojanowska abojanowska@swps.edu.pl

1 University of Social Sciences and Humanities, Uniwersytet SWPS, Wydział Zamiejscowy w Poznaniu, ul. gen, Tadeusza Kutrzeby 10, 61-719 Poznań, Poland of functioning needs to be expanded. Researchers suggest that we need to analyze the role of other (non-trait) dimensions of personality for well-being (Steel et al. 2018). Others stress, that we need a more broad approach to well-being (not limited to subjective/hedonic well-being; Waterman et al. 2010).

Firstly, most conceptions of personality indicate, that stable dispositions or traits are not its only element and that culturally determined and more dynamic aspects of functioning should also be treated as an integral part of personality. This has recently been proposed in the integrative model of personality (McAdams and Pals 2006) and earlier also by McCrae and Costa (McCrae 1996; McCrae and Costa 1999; McCrae and Sutin 2018). Secondly, conceptions of well-being suggest that subjective or hedonic well-being is not the only vital area of well-being experience. This has already been proposed in 1989 by Carol Ryff, but has recently gained momentum with the new general conception of eudaimonia proposed by Waterman et al. (2010). Consequently, new gaps in the knowledge on well-being and personality have been identified: not only traits, but also individual level culture expressed in values must be analyzed for their impacts on well- 
being (Steel et al. 2018); and the conceptualizations of well-being in these studies should also include the eudaimonic perspective.

In the present study, we will look at preliminary results on the links between temperament traits, values and the hedonic and eudaimonic well-being. This will be done basing on a small sample of Polish adults, but the results seem convincing enough to formulate more sophisticated hypotheses for future research.

\section{Hedonic and Eudaimonic Well-Being}

Well-being is usually conceptualized according to one of two main perspectives: hedonic and eudaimonic (Deci and Ryan 2008). The hedonic perspective is expressed in the subjective well-being model (Diener 2000) and the eudaimonic in Waterman's general eudaimonic well-being (Waterman et al. 2010). Subjective well-being includes positive affect, negative affect and satisfaction with life. In this conception people evaluate their own life with regard to individual criteria (satisfaction with life) and report on their affective experience. Eudaimonic well-being expresses the realization of one's potential, one's daimon. It can be measured with a general index, where people express to what extent they fulfil their own potential (Waterman et al. 2010). In the present study we will analyze how these two dimensions of well-being relate to traits and value dimensions.

\section{Two Levels of Personality}

Numerous classic and modern analyses showed that personality is responsible for stable differences in the experience of well-being (Bojanowska and Zalewska 2017; Brickman and Campbell 1971; Costa and McCrae 1980). According to these studies, the differences in well-being are stable and individuals have their individual baseline of well-being, determined by stable individual differences. Even after significant positive or negative life events, individual experience of well-being goes back to its baseline (Brickman and Campbell 1971). Studies have shown that high Extraversion and low Neuroticism constitute the 'happy personality' (the baseline is set at a 'happy' level; Costa and McCrae 1980). Newer analyses pointed out that configurations of stable temperament traits that express a preference for high stimulation combined with high stimulation processing capacity constitute a 'happy temperament' (Bojanowska and Zalewska 2016).

Recently, however, researchers suggested that there is a need for a more integrated model of personality that would go beyond the classic trait-only approach (Back 2017), especially when it comes to studying well-being (Zalewska et al. 2018). Two main theories can be used in this context: McCrae and Costa's Five Factor Theory of Personality (McCrae 1996; McCrae and Costa 1999; McCrae and Sutin 2018) and McAdams and Pals's personality conception (McAdams and
Pals 2006). In both of these conceptions traits are accompanied by socio-cognitive constructs, which express characteristic adaptations developed in the course of lifespan. These adaptations include values, attitudes, skills and beliefs.

In the present study, the level of traits is represented by stable, partly biologically determined temperament traits described in the Regulative Theory of Temperament (Strelau 2008) and the level of characteristic adaptations is represented by values (Schwartz 2007; Schwartz et al. 2012). Separately, each of these dimension sets have been known to impact wellbeing (Bojanowska and Zalewska 2017; Schwartz and Sortheix 2018a), although most analyses have focused only on the subjective well-being (not on eudaimonic).

\section{Regulative Theory of Temperament - Traits and Well-Being}

According to the Regulative Theory of Temperament, temperamental dimensions refer to formal aspects of behaviour, with regard to its energetic and temporal characteristics (Strelau and Zawadzki 1995, see also a summary of the conception in Kandler et al. 2013). Six traits have been listed:

1) Briskness (BR): tendency to react quickly, keep a high tempo and to easily shift from one behaviour to another in response to changes in the surroundings;

2) Perseveration $(\mathrm{PE})^{1}$ : tendency to continue and to repeat behaviour after the stimulus evoking this behaviour had stopped acting;

3) Emotional reactivity (ER): tendency to react intensely to emotion-generating stimuli, high emotional sensitivity and in low emotional endurance;

4) Endurance (EN): ability to react adequately to situations that demand long-lasting or highly stimulating activity and under intense external stimulation;

5) Activity (AC): tendency to undertake highly stimulating behaviour;

6) Sensory sensitivity (SS): ability to react to weak sensory stimuli. $^{2}$ (Strelau and Zawadzki 1995; Strelau 2008)

Five out of six of these traits were found to be related to subjective well-being (excluding Sensory Sensitivity; Bojanowska and Zalewska 2017). Activity, Endurance and Briskness had positive effects, Emotional reactivity had negative effects and Perseveration enhanced both the positive and negative affect. The beneficial role of Briskness was also demonstrated in studies on stress (Zawadzki and Popiel 2012;

\footnotetext{
${ }^{1}$ Originally, Strelau and Zawadzki (1995) used the term 'Perseverance', but it caused misunderstandings, so recent publications use the term 'Perseveration' (Strelau 2008).'

2 this trait will not be analyzed; earlier publications showed that it was not associated with well-being
} 
Fruehstorfer et al. 2012) and the beneficial role of Endurance in studies on burnout (Cieslak et al. 2008). Higher Briskness translates into a faster pace, easy shifting between activities and this leads to a more diverse experience that may facilitate higher satisfaction and positive affect. Higher Endurance expresses a person's ability to function effectively in a wider array of circumstances and to resist distractions. This may lead to greater satisfaction, provide more opportunities for the experience of positive emotions and shield from negative emotions, because highly enduring individuals feel tired only when faced with a lot of stimulation. Higher Activity seems to be connected to an advantageous mood profile. A more active person can engage in multiple activities and this may enhance satisfaction. The function of Perseveration is somewhat unclear. Its direct associations with subjective well-being indicated that it enhances both the negative and the positive affect, but studies on burnout and coping suggested that its high levels were maladaptive (Heszen 2012; Rzeszutek and Schier 2014). Emotional Reactivity got perhaps the widest attention in recent literature on quality of life. Its high levels were linked to decreased well-being indices and job satisfaction and to increased stress and anxiety (Bojanowska and Zalewska 2011, 2017; Zalewska 2011).

There are no studies on the functions of temperament traits for eudaimonic well-being. However, we expect that these relationships will be similar (in terms of directions) but weaker than for subjective well-being, especially compared to the affective component. The functions of a number of these temperament traits refer directly to emotionality (e.g. Emotional reactivity, Endurance) so they seem to be natural determinants of affective well-being. Others may impact engagement in numerous activities and goal attainment (e.g. Activity, Briskness, Endurance) that translate into satisfaction, so they may also help realize a person's potential and enhance eudaimonic well-being. We therefore hypothesize $(\mathrm{H} 1)$, that temperament traits predict subjective well-being and eudaimonic well-being (positive effects of Activity, Endurance, Briskness; negative effects of Emotional Reactivity, ambiguous effects of Perseveration). Mostly, we expect the effects for the affective component of well-being to be stronger than for satisfaction with life and for eudaimonic well-being.

\section{Circle of Values - Characteristic Adaptations and Well-Being}

Steel, Taras, Uggerslev and Bosco (Steel et al. 2018) state that well-being may be impacted by values. As suggested by McAdams and Pals (2006) values are one of the aspects of human personality. One of the most universal and current theories about human values was proposed by Schwartz (1992) and has been undergoing a process of constant improvement ever since the original publication. According to
Schwartz, values guide human behaviour and organize people's lives. Individual value hierarchies express what a person thinks is important in life, these are the ultimate ends that people think are important (Schwartz 2007; Schwartz et al. 2012). Schwartz lists values that are near universal and basic (Schwartz et al. 2012, verified in Poland by Cieciuch 2013). According to his model, the catalogue of individual values forms a circular motivational continuum. Adjacent values can be pursued simultaneously, because they share motivational meanings. One of the most recent set of basic values confirmed in intercultural research includes 19 values that can be grouped into four higher order dimensions: Openness to change, Conservation, Self-enhancement and Selftranscendence (Sortheix and Schwartz 2017). Openness to change, expresses values such as self-direction, stimulation or hedonism; Conservation, includes security, tradition and humility; Self-enhancement includes achievement and power values; and Self-transcendence universalism and benevolence. Various groupings of these values are possible, but in the present study we will analyze these four factors.

Relationships between values and subjective well-being have already been investigated to some extent (Bobowik et al. 2011; Bull and Mittelmark 2008; Joshanloo and Ghaedi 2009; Oishi et al. 1999; Sagiv and Schwartz 2000; Sortheix and Lönnqvist 2015). Results have shown that in general valuing Openness to change and Self-transcendence may promote subjective well-being, while Self-enhancement and Conservation may be linked to poorer subjective wellbeing (see: Sortheix and Schwartz 2017 for an overview). Fewer researchers have shown links between values and eudaimonic well-being. Joshanloo and Ghaedi (2009) showed that psychological and social well-being were positively related to some aspects of Self-enhancement and Openness to change and negatively to Conservation and Self-transcendence. Cohen and Shamai (2009) found positive relationships between psychological well-being and the values of benevolence, self-direction, and achievement (representing Self-transcendence, Openness and Self-enhancement), and a negative relationship for the values of power and tradition (part of Selfenhancement and Conservation). Bojanowska and Piotrowski (2017) showed that in Poland, Openness to change and Selftranscendence were linked to higher scores in some aspects of psychological well-being, while Conservation and Selfenhancement were linked to lower scores in some other aspects of psychological well-being (as conceptualized by Ryff 1989). Additionally, Conservation had some positive relationships (greater sense of purpose in life) and Openness to change had some negative relationships (weaker sense of purpose in life) with well-being. These analyses use the measures of psychological/social well-being to represent the eudaimonic perspective. We found no analyses on the relationships between values and general eudaimonic well-being (as conceptualized by Waterman et al. 2010). 
Basing on the research mentioned above we expect, that (H2) Self-transcendence and Openness to change correlates positively with well-being. With the little and conflicting data for the two remaining dimensions - Conservation and Selfenhancement - it would be difficult to formulate a clear and well-informed hypothesis, so we formulated a research question: How are Conservation and Self-enhancement values related to well-being? What are the directions of these relationships - are some of them adaptive (enhancing well-being) while others maladaptive (hampering well-being)? Are these relationships similar for all components of well-being - hedonic and eudaimonic?

As discussed above, the relationships between traits and well-being have already been established. Therefore, we decided to introduce values as possible predictors only after controlling for trait impacts. ${ }^{3}$

\section{Method}

\section{Participants}

$N=130^{4}$ adult participants (from 25 to 50 years old, $M=$ $35.81, S D=8.01)$ were recruited through social media posts (50\% were women; $15 \%$ with primary or vocational education, $34 \%$ with high school education, $51 \%$ were either students or had a university degree; $29 \%$ lived in rural areas, $45 \%$ in smaller or medium towns, $26 \%$ in bigger cities). They filled out the questionnaires on-line, participated voluntarily and were not offered payment for participation. The study was approved by the institutional ethics committee. Informed consent was obtained from all participants who took part in the study.

\section{Measures}

Temperament Temperamental traits were measured using Formal Characteristics of Behaviour - Temperament Inventory - short form (based on Zawadzki and Strelau 1997). These traits were Briskness (e.g. I usually do things quickly, e.g. house chores, tidying), Perseveration (e.g. Before falling asleep, I go back to conversations I had that day), Emotional Reactivity (e.g. I lose confidence when someone criticizes me), Endurance (e.g. I am able to keep working despite being tired), and Activity (e.g. I organize my holidays in such a way that I get a lot of new experiences) (Strelau and Zawadzki 1995; Strelau 2008). There were 7 items referring to each trait, with yes/no answers. A higher index indicated a

\footnotetext{
${ }^{3}$ We also introduced interactions between each trait and each value dimension in the third step but the $r$ change was not significant for any of the well-being components, so these will not be reported

4 one participant dropped, they answered all questions by marking option ' 3 ',
}

higher level of a particular trait. All Cronbach's alphas are reported in Table 1.

Values We used Schwartz's PVQ-RR (Portraits Value Questionnaire - Revised) adapted to Polish by Cieciuch (2013). The questionnaire consists of 19 values, 3 items per value with answer options from 1-not like meat all to 6-very much like me. For example, 'It is important to him/her to maintain traditional values or beliefs' referring to the value of tradition (Cieciuch 2013). Higher scores indicate that the value is important to the person. The scores for the four value dimensions Openness to change, Self-enhancement, Selftranscendence and Conservation were calculated by averaging raw scores of all of their components. Consequently, a higher score indicated that a value is important.

Subjective Well Being Indices Positive and Negative Affect were measured using Positive and Negative Affect Schedule - PANAS (Watson et al. 1988) translated into Polish with a back-translation (adapted by Bojanowska 2013). The measure includes a list of 10 adjectives referring to Positive (e.g. interested, excited) and 10 to Negative Affective states (e.g. guilty, ashamed) and respondents were asked to indicate how intensely they had felt this way during two weeks before the study. The scale ranged from 1 (only slightly or not at all) to 5 (extremely).

Satisfaction with Life was measured using Satisfaction with Life Scale - SWLS (Diener et al. 1985), Polish version adapted by the authors. Participants indicated to what extent they agreed with the statements about their lives (e.g. In most ways my life is close to my ideal) on a scale from 1 (I definitely disagree) to 7 (I definitely agree). Higher scores expressed higher Life Satisfaction.

Eudaimonic Well-Being Indices General eudaimonic wellbeing was measured with Questionnaire for Eudaimonic Well-being (Waterman et al. 2010) adapted to Polish by Kłym et al. (2014). The questionnaire consists of 21 items (e.g. I believe I know what my best potentials are and I try to develop them whenever possible) on a scale from 1 (Strongly agree) to 7 (Strongly disagree). Higher scores expressed higher well-being.

\section{Analytic Strategy}

We conducted four hierarchical regression analyses, separately for each well-being component - Positive Affect, Negative Affect, Satisfaction and Eudaimonic Well-being. Since the impacts of temperament for well-being are relatively wellestablished for most of these dimensions and since temperament is treated as the most basic level of personality in McAdams' and Pals' conception (McAdams and Pals 2006), we included them in the first step of the analysis. Dimensions 
Table 1 Means, standard deviations, internal consistencies and intercorrelations between well-being indices and temperament traits

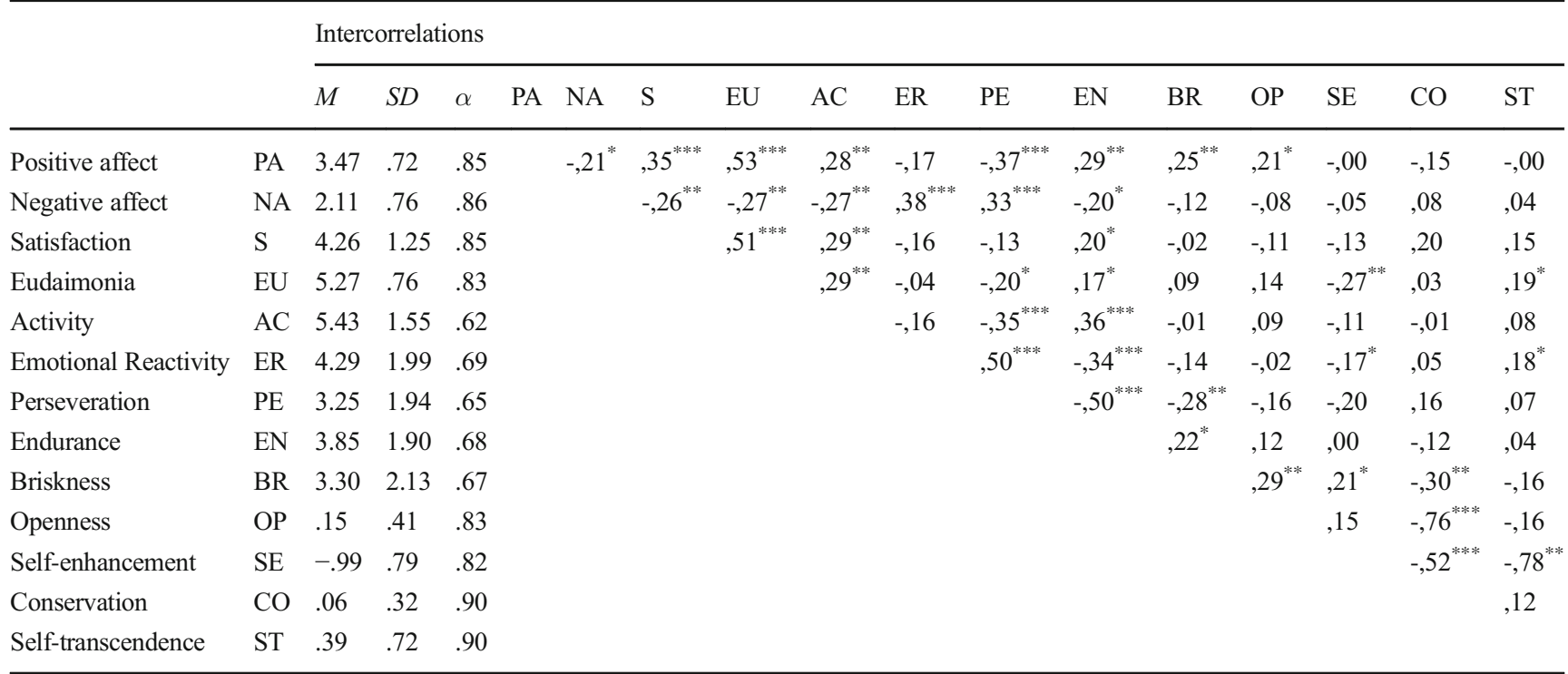

Note: $* p<0.05 * * p<0.01 * * * p<0.001$

expressing values were introduced in the second step of the regression model.

\section{Results}

\section{Descriptive Statistics and Intercorrelations}

Table 1 shows descriptive statistics. All scales demonstrated sufficient reliabilities. Well-being indices were weakly to moderately correlated. Correlations between temperament and hedonic well-being were consistent with previous data (positive effects for Activity, Briskness, Endurance, negative for Perseveration and Emotional reactivity). Similar relationships were found for eudaimonic well-being (positive correlation with Briskness and Endurance, negative with Emotional reactivity and Perseveration). Self-enhancement was related negatively with eudaimonic well-being, Self-transcendence was related positively. Additionally, Openness to change was positively related to Positive Affect.

Regression analyses showed that temperament traits significantly predicted all three components of hedonic well-being and eudaimonic well-being (only through Activity). Consistently with earlier findings, Activity translated into higher well-being in all aspects, including the eudaimonic, higher Emotional Reactivity translated into higher Negative Affect, higher Perseveration was linked to lower Positive Affect and higher Briskness to higher Positive Affect. The value dimensions added significantly to the proportion of explained variance only for the eudaimonic well-being, but not for hedonic. All four dimensions contributed to this effect higher Openness, Self-transcendence and Conservation values and lower Self-enhancement translated into higher eudaimonic well-being. Positive effects of Openness and Self-transcendence are consistent with our hypothesis, but limited to eudaimonic well-being. The post-hoc power analysis with the use of G*Power 3.1. (Faul et al. 2009) has indicated an adequate power of our study (from . 75 to .98 depending on the dependent variable (Table 2).

\section{Discussion}

We hypothesised that temperamental traits (Strelau and Zawadzki 1995) and values (Schwartz 1992) could be related to different facets of well-being. Earlier studies have suggested that temperamental characteristics such as Briskness, Endurance, and Activity were positively and Emotional reactivity was negatively related to hedonic well-being (Bojanowska and Zalewska 2017) but the links between temperament and eudaimonic well-being have not been previously analyzed. Reports on the effects of values on well-being suggested that Openness to change and Self-transcendence could impact hedonic and eudaimonic aspects of well-being in a positive way. The focus of our study was to provide the first empirical analysis of the joint influence of temperamental traits and values on those two facets of well-being.

\section{Temperament and Subjective Well-Being - Confirmation of Earlier Findings}

Our results confirm that temperamental characteristics have a broad and general impact on well-being. High Activity translated 
Table 2 Predictors of positive affect, negative affect, satisfaction with life and eudaimonic well-being - regression analysis

\begin{tabular}{|c|c|c|c|c|c|c|c|c|c|c|c|c|c|c|c|c|}
\hline \multirow[t]{2}{*}{ Predictor } & \multicolumn{4}{|c|}{ Positive affect } & \multicolumn{4}{|c|}{ Negative affect } & \multicolumn{4}{|c|}{ Satisfaction } & \multicolumn{4}{|c|}{ Eudaimonic well-being } \\
\hline & $\Delta \mathrm{R}^{2}$ & $\beta$ & CI & & $\Delta \mathrm{R}^{2}$ & $\beta$ & CI & & $\Delta \mathrm{R}^{2}$ & $\beta$ & $\mathrm{CI}$ & & $\Delta \mathrm{R}^{2}$ & $\beta$ & CI & \\
\hline Step 1. & $.20 * * *$ & & & & $.20 * * *$ & & & & $.11 *$ & & & & $.11 *$ & & & \\
\hline Activity & & $.18^{*}$ & .01 & .16 & & $-.19 *$ & -.18 & -.01 & & $.25 *$ & .05 & .35 & & $.25^{*}$ & .65 & 4.4 \\
\hline Emotional Reactivity & & .03 & -.06 & .08 & & $.30 * *$ & .04 & .19 & & -.11 & -.20 & .05 & & .08 & -.95 & 2.20 \\
\hline Perseveration & & $-.24 *$ & -.17 & -.02 & & .12 & -.04 & .13 & & .05 & -.11 & .18 & & -.11 & -2.70 & .95 \\
\hline Endurance & & .08 & -.04 & .10 & & .04 & -.06 & .09 & & .10 & -.07 & .20 & & .04 & -1.33 & 2.03 \\
\hline Briskness & & $.17 *$ & .02 & .12 & & -.05 & -.08 & .04 & & -.04 & -.13 & .08 & & .06 & -.85 & 1.81 \\
\hline Step 2. & .01 & & & & .02 & & & & .03 & & & & $.08 *$ & & & \\
\hline Openness to change & & & & & & & & & & & & & & $.34 * *$ & & \\
\hline Self-enhancement & & & & & & & & & & & & & & $-.29 * *$ & & \\
\hline Conservation & & & & & & & & & & & & & & $.31 *$ & & \\
\hline Self-transcendence & & & & & & & & & & & & & & $.20^{*}$ & & \\
\hline $\mathrm{R}^{2}$ & & .20 & & & & .20 & & & & .11 & & & & .19 & & \\
\hline Adjusted $\mathrm{R}^{2}$ & & .17 & & & & .17 & & & & .07 & & & & .08 & & \\
\hline$N$ & & 12 & & & & 125 & & & & 125 & & & & 12 & & \\
\hline
\end{tabular}

Note: $* \mathrm{p}<0.05 * * \mathrm{p}<0.01 * * * \mathrm{p}<0.001$

into higher well-being indices, high Emotional Reactivity predicted higher Negative Affect, high Perseveration predicted lower Positive Affect, high Briskness predicted higher Positive Affect. An earlier study (Bojanowska and Zalewska 2017) found more temperamental effects on subjective well-being, but the sample in that study was substantially larger so it might have been easier to establish significant effects. Despite our small sample, the effects we found are consistent with the functions of temperament traits discussed in earlier research (e.g. Strelau 2008).

Firstly, higher levels of Activity were connected to higher Positive Affect and Satisfaction, and to lower Negative Affect. The role of this trait is therefore pretty much straightforward higher Activity promotes the experience of positive emotions, shields from negative emotions and facilitates engagement in various tasks, that in turn may promote Satisfaction. This trait overlaps with Extraversion (Zawadzki and Strelau 1997) and it is a part of the happy personality-happy temperament configuration (Costa and McCrae 1980; Bojanowska and Zalewska 2016).

Secondly, high Emotional Reactivity was linked to lower Negative Affect. People with lower Emotional Reactivity are more emotionally stable and they tend not to interpret stimuli in emotional terms (Strelau 2008) and to react with less negative emotions as compared to highly emotionally reactive individuals (Zalewska 2011). High Emotional Reactivity is linked to more negative affect, possibly through a decreased effectiveness in stress (Strelau 2008).

Thirdly, higher Perseveration predicted lower Positive Affect. This is consistent with the functions of this trait discussed in theory (Strelau 2008), but inconsistent with empirical data (Bojanowska and Zalewska 2017), which suggested that high Perseveration could promote the experience of positive emotions. Here we found an inverse effect - higher Perseveration translated into lower Positive Affect and this is consistent with the definition of this trait. Originally, Strelau (2008) suggested that high Perseveration may not be adaptive, as it translates into a lingering reaction to a stimulus after it stopped acting. If Perseveration is linked to lower Positive Affect it means that this lingering reaction can cause stress, as it may not be adequate to objective circumstances or express a tendency to ruminate about things past.

Finally, lower Briskness predicted lower Positive Affect. This suggests that the inability to shift quickly between tasks may result in smaller benefits of engagement in tasks, because a person who is not brisk may have difficulties with managing energetic resources. Earlier findings suggested that this trait impacts the negative affect (Bojanowska and Zalewska 2017), but here the effect was limited to the Positive Affect. Nonetheless, higher Briskness seems beneficial for at least some aspects of subjective well-being.

\section{New Findings: Predictors of Eudaimonic Well-Being - Activity and Values}

The main aim of the present study was to fill gaps in our knowledge of the experience of well-being beyond subjective well-being and temperament. As stated in the introduction, there is a significant dearth of research on eudaimonic wellbeing determinants and on the function of values for hedonic and eudaimonic well-being (Steel et al. 2018). As this is 
mainly a pilot study, the findings discussed below may be used to establish new hypotheses for further research, however, because of the small sample size they need to be treated with caution.

In the present study, we found that eudaimonic well-being was predicted by Activity and by all four value dimensions. Compared to the predictors of hedonic (subjective) well-being, the experience of eudaimonia seems to be impacted by a more complex array of factors. Possibly, this dimension of well-being is more fluent, its experience may be reported basing on a more reflective insight into numerous areas of functioning.

Firstly, Activity seems to promote eudaimonic well-being. Eudaimonic well-being expresses the extent to which a person feels that she or he fulfils her or his potential, so the more active a person is (Waterman et al. 2010), the more he or she actually engages in goals and tasks that may lead to fulfilling this potential. Until now, this might have seemed like an obvious hypothesis, but there were no studies that would confirm this empirically. It seems that it may be more difficult to experience eudaimonia when a person has trouble with initiating engagement in numerous activities and entering various social roles that are facilitated by the temperamental trait of Activity. This mechanism also suggests that the baseline of well-being (Brickman and Campbell 1971) may refer not only to hedonic well-being, but that temperament may partly determine predispositions for a baseline experience of eudaimonia.

Secondly, we found that value dimensions predict eudaimonic well-being. Openness to change, Conservation and Self-transcendence were positive predictors and Selfenhancement was a negative predictor of eudaimonic wellbeing. Earlier studies consistently showed that Openness to change and Self-transcendence have positive relationships with well-being (Schwartz and Sortheix 2018b). Our study is congruent with these findings, in that these two dimensions may have a positive function. However, we did not find effects for subjective well-being (possibly due to a small sample size) but found them for eudaimonic well-being. Consequently, we suspect that hedonism with independence in though and action (contributing to Openness to change) and benevolence with universalism (contributing to Self-transcendence) express motivations that help realize a person's potential. Schwartz (2012) and Sortheix and Schwartz (2017) suggested that these two value dimensions express a self-expansive growth orientation. Consequently, people who share this need for self-expansion are more likely to engage in tasks that help them realize their potential and experience eudaimonia.

These direct links with well-being are consistent with what has been called 'first generation studies' that identified healthy and unhealthy values (Schwartz and Sortheix 2018a). In these studies Conservation was identified as an unhealthy value. We found this value to be 'healthy', so our finding is inconsistent with these first generation studies. On the other hand, second generation studies suggested, that the relationships between values and well-being may be moderated by social context. One of the most commonly discussed moderation factor is the person-group fit - a person who has the same values as her or his social environment experiences higher well-being (e.g. Sortheix and Lönnqvist 2015; Khaptsova and Schwartz 2016). This explains why Conservation values may be 'healthy' in Poland. As suggested by Hofstede, Polish society is characterised by uncertainty avoidance, normative orientation and a lot of restraint (Hofstede Insights 2018). Consequently, people who have values reflecting these dimensions, such as anxiety avoidance (congruent with uncertainty avoidance at a national level) or tradition (consistent with normative orientation at a national level) should be happier. In other words, Conservation is linked to higher eudaimonic well-being in our sample, because individuals who value tradition and safety may find it easier to engage in tasks that realize these values when numerous people around them share these values.

We also found a negative relationship between Selfenhancement and eudaimonic well-being. This finding is consistent with earlier research (see Schwartz \& Sortheix, 2018 for an overview). Self-enhancement values express a person's extrinsic values (Ryan and Deci 2001), a need to pursue selfinterested dominance and wealth. Extrinsic motivations may elicit negative reactions from others (Schwartz \& Sortheix, 2018), but also they do not seem to express processes driven by self-actualization, so they may actually hamper the realization of one's 'true self' that is central to the concept of eudaimonic well-being (Waterman et al. 2010).

\section{Conclusions and Limitations}

The present study has its limitations: a small sample size, correlational study design and participant recruitment through social media post. Since social media profiles base on friend networks, it is possible that our sample was limited to a specific group of people that share common interests or some demographics (such as e.g. place of residence). This may limit the validity of the findings. However, it seems that the effects we found may be helpful in establishing hypotheses for future investigations into well-being.

The most general conclusion from this study is that hedonic and eudaimonic well-being have their own unique sets of predictors and that while hedonic well-being is mostly determined by stable personality traits, eudaimonic well-being is subject to more diverse impacts of traits and values. If hedonic well-being is determined mostly by stable traits, it may be difficult to modify. This may be frustrating for psychology in practice - traits are stable and difficult (or impossible) to influence so it may be difficult to enhance hedonic well-being in a stable way. Eudaimonic well-being seems to be linked to values, which are socio-cognitive constructs, so they are, by 
definition, constructed in social processes. This means that if future studies confirm a cause-effect direction of influence between values and well-being, we may establish which values may be shaped in a way that promotes well-being. Additionally, eudaimonic well-being seems to be related to hedonic well-being. According to Waterman et al. (2010) hedonic well-being may actually be a by-product of eudaimonic well-being to some extent. Therefore, values that promote eudaimonic well-being may also lead to the experience of greater hedonic well-being indirectly.

\section{Compliance with Ethical Standards}

Ethical Approval All procedures performed in studies involving human participants were in accordance with the ethical standards of the institutional and/or national research committee (the Polish Code of Professional Ethics for the Psychologist; Polish Psychological Association) and with the 1964 Helsinki declaration and its later amendments or comparable ethical standards.

Informed Consent Informed consent was obtained from all individual participants included in the study.

Conflict of Interest The authors declare that they have no conflict of interest and have no financial or personal relationship with a third party whose interests could be positively or negatively influenced by the article's content.

Open Access This article is distributed under the terms of the Creative Commons Attribution 4.0 International License (http:// creativecommons.org/licenses/by/4.0/), which permits unrestricted use, distribution, and reproduction in any medium, provided you give appropriate credit to the original author(s) and the source, provide a link to the Creative Commons license, and indicate if changes were made.

\section{References}

Back, M. D. (2017). Reaching out and digging deeper - Towards integration in personality psychology and beyond. European Journal of Personality, 31. https://doi.org/10.1002/per.2130.

Bobowik, M., Basabe, N., Paez, D., Jimenez, A., \& Bilbao, M. A. (2011). Personal values and well-being among Europeans, Spanish natives and immigrants to Spain: Does the culture matter? Journal of Happiness Studies, 12, 401-419. https://doi.org/10.1007/s10902010-9202-1.

Bojanowska, A. (2013). Sezony szczęścia. Jakość życia z perspektywy rozwojowej w zależności od cech temperamentu i wsparcia społecznego [Seasons of happiness. A developmental perspective on quality of life - the role of temperament and social support]. (unpublished doctoral dissertation). SWPS University, Warszawa, Poland.

Bojanowska, A. \& Piotrowski, K. (2017). Values and psychological wellbeing among adolescents - Are some values 'healthier' than others? European Journal of Developmental Psychology, 1-15, doi:https:// doi.org/10.1080/17405629.2018.1438257.

Bojanowska, A., \& Zalewska, A. M. (2011). Subjective well-being among teenagers of different ages: The role of emotional reactivity and social support from various sources. Studia Psychologiczne, 49(5), 5-21. https://doi.org/10.2478/v10167-010-0037-5.
Bojanowska, A.,\& Zalewska, A.M. (2016). Happy temperament? Four types of stimulation control linked to four types of subjective wellbeing. Journal of Happiness Studies, accepted for publication, published with open access at Springerlink.com. Journal of Happiness Studies. https://doi.org/10.1007/s10902-016-9777-2.

Bojanowska, A., \& Zalewska, A. M. (2017). Temperamental predictors of subjective well-being from early adolescence to mid-life: The role of temporal and energetic regulation. International Journal of Psychology. https://doi.org/10.1002/ijop.12414.

Brickman, P., Campbell, D. T. (1971). Hedonic relativism and planning the food society. [in:] M. H. Appley (red.), Adaptation-level Theory (s.287-305). New York: Academic Press.

Bull, T., \& Mittelmark, M. B. (2008). Subjective well-being among employed lone mothers in Europe: The effects of level of work/ family conflict and self-enhancement versus self-transcendence value orientation. International Journal of Mental Health Promotion, 10(3), 26-33. https://doi.org/10.1080/14623730.2008.9721766.

Cieciuch, J. (2013). Ksztaltowanie się systemu wartości od dzieciństwa do wczesnej dorostości. Warszawa: LiberiLibri.

Cieslak, R., Korczynska, J., Strelau, J., \& Kaczmarek, M. (2008). Burnout predictors among prison officers: The moderating effect of temperamental endurance. Personality \& Individual Differences, 45(7), 666-672. https://doi.org/10.1016/j.paid.2008. 07.012 .

Costa, P. T., \& McCrae, R. (1980). Influence of extraversion and neuroticism on subjective well-being: Happy and unhappy people. Journal of Personality and Social Psychology, 38(4), 668-678.

Deci, E. L., \& Ryan, R. M. (2008). Hedonia, eudaimonia, and well-being: An introduction. Journal of Happiness Studies, 9(1), 1-11.

Diener, E. (2000). Subjective well-being: The science of happiness and a proposal for a national index. American Psychologist, 55(1), 34- 43. https://doi.org/10.1037/0003-066X.55.1.34.

Diener, E., Emmons, R. A., Larsen, R. J., \& Griffin, S. (1985). The satisfaction with life scale. Journal of Personality Assessment, 49, 71. https://doi.org/10.1207/s15327752jpa4901_13.

Faul, F., Erdfelder, E., Buchner, A., \& Lang, A. G. (2009). Statistical power analyses using $\mathrm{G}^{*}$ power 3.1: Tests for correlation and regression analyses. Behavior Research Methods, 41, 1149-1160 https:// doi.org/10.3758/BRM.41.4.1149.

Fruehstorfer, D. B., Veronie, L., Cremeans-Smith, J. K., \& Newberry, B. H. (2012). Predicting illness-related outcomes with FCB-TI trait pairs: Examining the nonadditive effects of FCB-TI perseveration. Journal of Individual Differences, 33(4), 248-256. https://doi.org/ 10.1027/1614-0001/a000070.

Heszen, I. (2012). Temperament and coping activity under stress of changing intensity over time. European Psychologist, 17(4), 326336. https://doi.org/10.1027/1016-9040/a000121.

Hofstede Insights (2018). Culture Compass ${ }^{\mathrm{TM}}$. Retrieved from: https:// www.hofstede-insights.com/country-comparison/poland/ [Online Resource].

Joshanloo, M., \& Ghaedi, G. (2009). Value priorities as predictors of hedonic and eudaimonic aspects of well-being. Personality and Individual Differences, 47(4), 294-298. https://doi.org/10.1016/j. paid.2009.03.016.

Kandler, C., Riemann, R., \& Angleitner, A. (2013). Patterns and sources of continuity and change of energetic and temporal aspects of temperament in adulthood: A longitudinal twin study of self- and peer reports. Developmental Psychology, 49(9), 1739-1753. https://doi. org/10.1037/a0030744.

Khaptsova, A., \& Schwartz, S. H. (2016). Life satisfaction and value congruence: Moderators and extension to constructed sociodemographic groups in a Russian national sample. Social Psychology, 47, 163-173.

Kłym, M., Karaś, D., Najderska, M., \& Cieciuch, J. (2014). Polish version of the Questionnaire for Eudaimonic Well-Being (QEWB). 
Referat na 28th International Congress of Applied Psychology, Paryż, Francja.

McAdams, D. P., \& Pals, J. L. (2006). A new big five: Fundamental principles for an integrative science of personality. American Psychologist, 61(3), 204-217.

McCrae, R. R. (1996). Integrating the levels of personality. Psychological Inquiry, 7, 353-356.

McCrae, R. R., \& Costa, P. T. (1999). A fi ve-factor theory of personality. In L. A. Pervin \& O. P. John (Eds.), Handbook of personality: Theory and research (pp. 139-153). New York: Guilford.

McCrae, R. R., \& Sutin, A. R. (2018). A fi ve-factor theory perspective on causal analysis. European Journal of Personality. Advance online publication. https://doi.org/10.1002/per.2134.

Oishi, S., Diener, E. F., Lucas, R. E., \& Suh, E. M. (1999). Cross-cultural variations in predictors of life satisfaction: Perspectives from needs and values. Personality and Social Psychology Bulletin, 25(8), 980 990. https://doi.org/10.1177/01461672992511006.

Ryan, R. M., \& Deci, E. L. (2001). On happiness and human potentials: A review of research on hedonic and eudaimonic well-being. Annual Review of Psychology, 52, 141-166.

Ryff, C. D. (1989). Happiness is everything, or is it? Explorations on the meaning of psychological well-being. Journal of Personality and Social Psychology, 57, 1069-1081.

Rzeszutek, M., \& Schier, K. (2014). Temperament traits, social support, and burnout symptoms in a sample of therapists. Psychotherapy, 51(4), 574-579. https://doi.org/10.1037/a0036020.

Sagiv, L., \& Schwartz, S. H. (2000). Value priorities and subjective wellbeing: Direct relationsand congruity effects. European Journal of Social Psychology, 30, 177-198.

Schwartz, S. H. (1992). Universals in the content and structure of values: Theory and empirical tests in 20 countries. In M. Zanna (Ed.), Advances in experimental social psychology (Vol. 25, pp. 1-65). New York: Academic Press https://doi.org/10.1016/S00652601(08)60281.

Schwartz, S. H. (2007). Universalism values and the inclusiveness of our moral universe. Journal of Cross-Cultural Psychology, 38(6), 711728. https://doi.org/10.1177/0022022107308992.

Schwartz, S. H. (2012). Do personal values underlie or undermine happiness? Cultural effects. Paper presented at the European Social Survey International Conference, Nicosia, Cyprus.

Schwartz, S. H., \& Sortheix, F. M. (2018a). Values and subjective wellbeing. In E. Diener, S. Oishi, \& L. Tay (Eds.), Handbook of wellbeing. Noba scholar handbook series: Subjective well-being. Salt Lake City, UT: DEF publishers. DOI:nobascholar.com.

Schwartz, S., Cieciuch, J., Vecchione, M., Davidov, E., Fischer, R., Beierlein, C., Ramos, A., Verkasalo, M., Lönnqvist, J.-E., Demirutku, K., Dirilen-Gumus, O., \& Konty, M. (2012). Refining the theory of basic individual values. Journal of Personality and Social Psychology, 103(4), 663-688.
Schwartz, S. H., \& Sortheix, F. M. (2018b). Values and subjective wellbeing. In E. Diener, S. Oishi, \& L. Tay (Eds.), handbook of wellbeing. Noba scholar handbook series: Subjective well-being. Salt Lake City, UT: DEF publishers. DOI:nobascholar.com.

Sortheix, F. M., \& Lönnqvist, J. (2015). Person-group value congruence and subjective well-being in students from Argentina, Bulgaria and Finland: The role of interpersonal relationships. Journal of Community \& Applied Social Psychology, 25(1), 34-48. https:// doi.org/10.1002/casp.2193.

Sortheix, F. M., \& Schwartz, S. H. (2017). Values that underlie and undermine well-being: Variability across countries. European Journal of Personality, 31(2), 187-201. https://doi.org/10.1002/per.2096.

Steel, P., Taras, V., Uggerslev, K. L., \& Bosco, F. A. (2018). The happy culture: A theoretical, meta-analytic and empirical review of the relationship between culture and wealth and subjective wellbeing. Personality and Social Psychology Review, 22(2), 128-169. https:// doi.org/10.1177/1088868317721372.

Strelau, J. (2008). Temperament as a regulator of behaviour: After fifty years of research. Clinton corners, New York: Eliot Werner Publications.

Strelau, J., \& Zawadzki, B. (1995). The formal characteristics of behaviour-Temperament inventory (FCB-TI): Validity studies. European Journal of Personality, 9, 207-229. https://doi.org/10. 1002/per.2410090304.

Waterman, A. S., Schwartz, S. J., Zamboanga, B. L., Ravert, R. D., Williams, M. K., Bede Agocha, V., et al. (2010). The questionnaire for Eudaimonic well-being: Psychometric properties, demographic comparisons, and evidence of validity. The Journal of Positive Psychology, 5(1), 41-61.

Watson, D., Clark, L. A., \& Tellegen, A. (1988). Development and validation of brief measures of positive and negative affect: The PANAS scales. Journal of Personality and Social Psychology, 54, 1063-1070. https://doi.org/10.1177/1073191108328890.

Zalewska, A. M. (2011). Relationships between anxiety and job satisfaction - Three approaches: "bottom-up", "top-down", and "transactional". Personality and Individual Differences, 50, 977-986. https://doi.org/10.1016/j.paid.2010.10.013.

Zalewska, A. M., Nezlek, J., \& Zieba, M. (2018). Integrated approach to personality and well-being. Polish Psychological Bulletin, 49(2), 128-130. https://doi.org/10.24425/119479.

Zawadzki, B., \& Popiel, A. (2012). Temperamental traits and severity of PTSD symptoms: Data from longitudinal studies of motor vehicle accident survivors. Journal of Individual Differences, 33(4), 257267. https://doi.org/10.1027/1614-0001/a000074.

Zawadzki, B., \& Strelau, J. (1997). Formalna Charakterystyka Zachowania - Kwestionariusz Temperamentu. Podrecznik. Warszawa: Pracownia Testów Psychologicznych PTP. 